\title{
Gray Comprehensive Evaluation Method on Coal Seam Water Injection in Order of Difficulty
}

\author{
Xiao Li Liu ${ }^{1 a, 2}$, Zhi Ye Zhang ${ }^{2,3}$, Meng Qian Li $^{2}$ \\ ${ }^{1}$ College of Resources \& Safety Engineering, China University of Mining \& Thchnology, Beijing, China \\ ${ }^{2}$ College of Mining Engineering, North China University of Science and Technology, China \\ ${ }^{3}$ Safety department, Tangshan Stainless Stell CO.,LTD, Hebei, China
}

\begin{abstract}
In order to evaluate the coal mine water injection accurately, the gray comprehensive evaluation is applied in this paper, the depth of coal seam, the development degree of coal seam crack, porosity, gas pressure in coal seam, wetting edge of coal, firmness coefficient of coal are chosen as the main index to evaluate the method of water injection into coal mine. The results show that the gray comprehensive evaluation model has a relatively high reliability and accuracy, which can be used to predict the difficulty degree of water injection.
\end{abstract}

Key words: coal seam water injection, gray comprehensive evaluation, influence factors, evaluation method

\section{Introduction}

Coal seam water injection method, which is widely used in coal mine production, is applied to prevention of rock burst, coal dust, coal and gas outburst. The effect of water injection in some places is good, while in other places is less effective, even is hard to be injected for some coal seams, so it is important to scientifically evaluate whether the coal seam can be injected into or the difficulty degree of water injection, which provides important references for the way and parameters of water injection.

There have been considerable studies about prediction of coal seam water injection in recent years, for example, the back-propagation artificial neural network method, the fisher discrimination method, which have gotten some achievements and have become hot spot in predicting coal seam water injection in order of difficulty, however these methods also have some shortcomings.

On the basis of expert judgment, gray comprehensive evaluation method is guided by gray correlation analysis theory. In order to predict the difficulty degree of water injection into coal seam accurately, gray comprehensive evaluation model is applied in the paper on the basis of gray system theory. Provided with 8 groups of related data instances of coal seam to predict, the results can be used as references for water injection parameters.

\section{Evaluation index of difficulty degree of water injection into coal seam}

The difficulty degree of water injection into coal seam

${ }^{\text {a }}$ Corresponding author: liuxiaoli996@163.com 
refers to the ability of coal adsorbing water: whether the water is easy to get into the porosity and cracks structure of coal, and in some cases which may contain whether the water is easy to run off from some cracks. In the course of water injection, if the water is hard to get into the pores and cracks structure of coal, or is easy to run off from the cracks, the effect of water injection will be influenced, even no effect, so the index of difficulty degree of water injection into coal seam is crucial to evaluate water injection.

With reference to the existing research results at home and abroad, the index' $\mathrm{s}$ accessible and universality in location prediction, the actual situation of typical mine at home and abroad where water injection is adopted in coal seams, the main index in this paper contains the buried depth, the development degree of coal seam crack, porosity, gas pressure in coal seam, wetting edge of coal, firmness coefficient of coal.

\section{(1) The buried depth}

The compression levels of pores and cracks are related to the formation pressure which is influenced by the buried depth. The water permeability coefficient decreased as the cracks are compressed and the pore volume decreased while the buried depth increases.

(2) The development degree of coal seam crack

The development degree of coal seam crack is an important factor affecting the coal seam water injection. In general, water is easy to be injected in high permeability coal seam.

(3) The porosity

The porosity has a direct effect on water injection. Whether the water is easy to be injected and the wetting effect are closely concerned with the nature water filling degree of coal seam and water permeability of crack which has a certain function with porosity.

(4) The gas pressure in coal seam

The gas pressure in coal seam is resistance to water injection, the effective pressure of water injection is that the water injection pressure minus the gas pressure. So in the high pressure coal seam, in order to get the same water injection volume, the water injection pressure should be improved, which increases the difficulty of water injection.
(5) The wetting edge of coal

The smaller the wetting edge of coal is, the more the capillary force is, which enhances the water injection and causes the water easily be injected.

(6) The firmness coefficient of coal

The firmness coefficient of coal comprehensively reflects the breakage degree of coal under a variety of ways. Practices show that if other conditions are similar, the less the firmness coefficient is, the easily the water is injected.

\section{Gray comprehensive evaluation method on coal seam water injection method in order of difficulty}

\subsection{Gray system evaluation model}

The basic idea of gray system evaluation is: confirming the correlation degree between comparative sequence and reference sequence according to the geometric similarity degree of family of curves composed of comparative sequence and family of curves composed by reference sequence. The more similarity of geometric between the curves composed by comparative sequence and the curves composed by reference sequence is the bigger the correlation degree is. For gray system evaluation of coal seam water injection, the comparative sequence is composed by all index value of one project.

$$
C_{i}(j)=\left\{C_{i}(1), C_{i}(2), \cdots, C_{i}(\mathrm{~m})\right\},
$$

In the formular $1, \mathrm{i}=1,2, \ldots, \mathrm{n}, \mathrm{n}$ represents the number of the project; $\mathrm{m}$ represents index number of each project.

The paper chooses 8 different sites in coal mine to evaluate the coal mine water injection. The evaluation indexes of the sites is presented in Table 1 . 
Table 1. The evaluation indexes of coal mine water injection in different sites of coal mine

\begin{tabular}{|c|c|c|c|c|c|c|}
\hline Number & $\begin{array}{l}\text { Buried depth } \\
\quad(\mathbf{m})\end{array}$ & $\begin{array}{c}\text { Development } \\
\text { degree of coal } \\
\text { seam } \\
\text { crack(number/50 } \\
\text { m) } \\
\end{array}$ & Porosity(\%) & $\begin{array}{l}\text { Gas pressure in } \\
\text { coal seam(MPa) }\end{array}$ & $\begin{array}{l}\text { Wetting edge of } \\
\text { coal }\left({ }^{\circ}\right)\end{array}$ & $\begin{array}{c}\text { Firmness coefficient } \\
\text { of } \operatorname{coal}\left(\mathbf{k g} / \mathrm{cm}^{2}\right)\end{array}$ \\
\hline 1 & 410 & 23 & 9.6 & 0.46 & 89 & 0.55 \\
\hline 2 & 360 & 33 & 12.8 & 0.38 & 26 & 0.65 \\
\hline 3 & 320 & 55 & 15.9 & 0.3 & 44 & 0.58 \\
\hline 4 & 365 & 26 & 39.2 & 0.32 & 31 & 0.90 \\
\hline 5 & 255 & 38 & 23.8 & 0.28 & 39 & 0.78 \\
\hline 6 & 635 & 21 & 7.8 & 0.51 & 68 & 0.76 \\
\hline 7 & 460 & 46 & 8.9 & 0.49 & 56 & 0.55 \\
\hline 8 & 365 & 38 & 16.5 & 0.32 & 75 & 0.65 \\
\hline
\end{tabular}

The matrix constructs according to the evaluation indexes of table 1:

$\left[\begin{array}{cccccc}410 & 23 & 9.6 & 0.36 & 89 & 0.55 \\ 360 & 33 & 12.8 & 0.38 & 26 & 0.65 \\ 320 & 55 & 15.9 & 0.3 & 44 & 0.58 \\ 365 & 26 & 39.2 & 0.32 & 31 & 0.90 \\ 255 & 38 & 23.8 & 0.28 & 39 & 0.78 \\ 635 & 21 & 7.8 & 0.51 & 68 & 0.76 \\ 460 & 46 & 8.9 & 0.49 & 56 & 0.55 \\ 365 & 38 & 16.5 & 0.32 & 75 & 0.65\end{array}\right]$

\subsection{Confirming the reference sequence}

When different locations in coal mine were made to be evaluated, the criterion should be made in accordance with the comparability and advanced principle which is the optimal value of each index. The optimal value is chosen in the light of the criterion which benefits the coal mine water injection. For example, the more the crack is developed, the bigger the porosity which benefits the coal mine water injection is, so the maximum value is chosen as the optimal value; where the gas pressure goes against the coal mine water injection, the minimum value was chosen as the optimal value. The optimal index set is:

$$
C_{0}(j)=\left\{C_{0}(1), C_{0}(2), \cdots, C_{0}(m)\right\}=
$$

$\{255,55,39.2,0.28,26,0.55\}$.

When the optimal index set is chosen, the matrix D was made as follows:

$$
D=\left[\begin{array}{cccccc}
255 & 55 & 39.2 & 0.28 & 26 & 0.55 \\
410 & 23 & 9.6 & 0.36 & 89 & 0.55 \\
360 & 33 & 12.8 & 0.38 & 26 & 0.65 \\
320 & 55 & 15.9 & 0.3 & 44 & 0.58 \\
365 & 26 & 39.2 & 0.32 & 31 & 0.90 \\
255 & 38 & 23.8 & 0.28 & 39 & 0.78 \\
635 & 21 & 7.8 & 0.51 & 68 & 0.76 \\
460 & 46 & 8.9 & 0.49 & 56 & 0.55 \\
365 & 38 & 16.5 & 0.32 & 75 & 0.65
\end{array}\right]
$$

\subsection{Standardization processing of the index value}

As the dimension and the magnitude of the evaluation index are different, so the evaluation index cannot be compared directly, the original index value should be standard handled in formula 5 :

$$
X_{i}(j)=\frac{C_{i}(j)}{C_{j}},
$$

In the above formula, $C_{j}=\frac{1}{n} \sum_{i=0}^{n} C_{i}(j)$ $j=1,2, \cdots, m$.

Nondimensionalize the table 1 we can get the following matrix: 


$D^{\prime}=\left[\begin{array}{llllll}0.0744 & 0.1642 & 0.2257 & 0.0864 & 0.0573 & 0.0921 \\ 0.1197 & 0.0687 & 0.0553 & 0.1111 & 0.1960 & 0.0921 \\ 0.1051 & 0.0985 & 0.0737 & 0.1173 & 0.0573 & 0.1089 \\ 0.0934 & 0.1642 & 0.0915 & 0.0926 & 0.0969 & 0.0972 \\ 0.1066 & 0.0776 & 0.2257 & 0.0988 & 0.683 & 0.1508 \\ 0.0745 & 0.1134 & 0.1370 & 0.0864 & 0.0859 & 0.1307 \\ 0.1854 & 0.0627 & 0.0449 & 0.1574 & 0.1498 & 0.1273 \\ 0.1343 & 0.1373 & 0.0512 & 0.1512 & 0.1233 & 0.0921 \\ 0.1066 & 0.1134 & 0.0950 & 0.0988 & 0.1620 & 0.1089\end{array}\right]$

$\left|\mathrm{x}_{0}(\mathrm{j})-\mathrm{x}_{\mathrm{i}}(\mathrm{j})\right|$ is used in matrix 6 , we can get the matrix 7:

$$
D^{\prime \prime}=\left[\begin{array}{cccccc}
0.0321 & 0.0507 & 0.1307 & 0.0123 & 0.1079 & 0.0168 \\
0.0307 & 0.0657 & 0.1520 & 0.0309 & 0 & 0.0168 \\
0.0190 & 0 & 0.1341 & 0.0062 & 0.0396 & 0.0050 \\
0.0321 & 0.0866 & 0 & 0.0123 & 0.011 & 0.0586 \\
0 & 0.0507 & 0.0887 & 0 & 0.0286 & 0.0385 \\
0.1109 & 0.1015 & 0.1808 & 0.071 & 0.0925 & 0.0352 \\
0.0599 & 0.0269 & 0.1744 & 0.0648 & 0.6608 & 0 \\
0.0321 & 0.0507 & 0.1307 & 0.0123 & 0.1079 & 0.0168
\end{array}\right]
$$

\subsection{Confirming the weight of each evaluation index}

the weight obtained by Delphi method is presented an formula 8 :

$W=\left[w_{1}, w_{2}, \cdots, w_{n}\right]=[0.15,0.25,0.18,0.23,0.08,0.11]$.

\subsection{Confirming the correlation degree}

According to gray system theory, when comparing sequence $C_{i}$ comparing to reference sequence $C_{0}$, we can get the correlation coefficient $\xi_{i}(j)$ of index $C_{i}(j)$ by formula 9 :

$$
\begin{gathered}
\xi_{i}(j)=\frac{\min _{i} \min _{j}\left|x_{0}(j)-x_{i}(j)\right|+\rho_{i} \max _{j} \max _{j}\left|x_{0}(j)-x_{i}(j)\right|}{\left|x_{0}(j)-x_{i}(j)\right|+\rho \max _{i} \max _{j}\left|x_{0}(j)-x_{i}(j)\right|}, \\
i=1,2, \cdots, n ; j=1,2, \cdots, \mathrm{m} .
\end{gathered}
$$

In above formula, $\rho$ is the discrimination coefficient, which effect is to improve the significant difference between correlation coefficients. $\rho$ is selected usually from 0 to 1 , generally $\rho=0.5$. So we can get the evaluation matrix of coal mine water injection as follows:

$\varepsilon=\left[\begin{array}{cccccc}0.9114 & 0.8670 & 0.7165 & 0.9641 & 0.7538 & 0.9516 \\ 0.9150 & 0.8341 & 0.6849 & 0.9145 & 1 & 0.9516 \\ 0.9456 & 1 & 0.7113 & 0.9816 & 0.8930 & 0.9851 \\ 0.9114 & 0.7923 & 1 & 0.9641 & 0.9678 & 0.8494 \\ 1 & 0.8670 & 0.7884 & 1 & 0.9203 & 0.8956 \\ 0.7487 & 0.7650 & 0.6463 & 0.8231 & 0.7813 & 0.9037 \\ 0.8465 & 0.9247 & 0.6545 & 0.8360 & 0.3333 & 1 \\ 0.9114 & 0.8670 & 0.7165 & 0.9641 & 0.7538 & 0.9516\end{array}\right]$

In order to compare in general, the correlation coefficient of each index is expressed in one value which is obtained in formula 11:

$$
\gamma_{i}=\sum_{j=1}^{n} \varepsilon_{i}(j) W_{j}
$$

Obviously, the bigger the value of $\gamma_{i}$ is, the better effect of coal mine water injection the site is.

$$
\begin{aligned}
& \gamma_{1}=\sum_{j=1}^{n} \varepsilon_{i}(j) W_{j}=0.8692 \\
& \gamma_{2}=\sum_{j=1}^{n} \varepsilon_{i}(j) W_{j}=0.8641 \\
& \gamma_{3}=\sum_{j=1}^{n} \varepsilon_{i}(j) W_{j}=0.9254 \\
& \gamma_{4}=\sum_{j=1}^{n} \varepsilon_{i}(j) W_{j}=0.9074 \\
& \gamma_{5}=\sum_{j=1}^{n} \varepsilon_{i}(j) W_{j}=0.9108 \\
& \gamma_{8}=\sum_{j=1}^{n} \varepsilon_{i}(j) W_{j}=0.8692 \\
& \gamma_{6}=\sum_{j=1}^{n} \varepsilon_{i}(j) W_{j}=0.7711
\end{aligned}
$$

From the above calculation, we can get the conclusion that:

(1) The sites from which are hard to be injected to 
which are easy to be injected are: site 6 , site 7 , site2, site1, site 8 , site 4 , site 5 , site 3 , where site 1 and site 8 are in the same difficulty when water is injected.

(2) In the paper, the biggest of the correlation degree is site 3 which is closest to the optimal value, so site 3 is the best site for coal mine water injection. When the 8 sites were compared, we can find that the development degree of coal seam crack and the porosity in site 3 is high and the gas pressure in coal mine in site 3 is small, so site 3 is the best site for water injection into coal seam.

(3) In the paper, site 6 is the worst place for water injection, where buried depth is large, the porosity is small, and the gas pressu1re in coal seam is high relatively.

\section{Conclusion}

(1) The paper analyzed the main indexes which can best reflects the coal mine water injection in order of difficulty, the buried depth, the development degree of coal seam crack, the porosity, the gas pressure in coal seam, the wetting edge of coal and the firmness coefficient of coal were chosen as the main indexes for coal mine water injection evaluation.

(2) The gray comprehensive evaluation model of coal seam water injection was constructed by gray system theory, which achieved good results by coal seam water injection evaluation of 8 different sites in coal mine.

(3) The conclusion presents important references for selection of process and parameters.

\section{References}

[1] Yuan Zhigang, Wang Hongtu, Hu Guozhong, Liu Nianping, Fan Xiaogang. Fisher discriminant analysis model and application of classifying difficulty degree of water infusion for coal seam, Journal of China Coal Society, 2011,34(4):638-642

[2] Guo Hongyu, Su Xianbo. Research on the mechanism of gas emmission inhibition in water-flooding coal seam[J] Journal of China Coal Society, 2010,35(6):928-931

[3] Qin Shuyu, Qin Wei, Zhao Jingfu. BP neural network method application in feasibility evaluation of water infusion for coal seam[J]. Chinese Journal of Geological Hazard and Control, 2006,17(3):87-90

[4] Hai Guozhi, Li Zongxiang, Qin Shuyu. Fuzzy classification analysis method for classifying difficulty degree of water infusion for coal seam[J]. Coal Science and Technology, 1993, 21(4):18-21 